\title{
High Pressure Processing of Meat and Meat Products: Application Aspects and Prospects of Use
}

\author{
Alexey Volkov ${ }^{1}$, Lyudmila Donskova ${ }^{2,}$, and Victoria Kotkova ${ }^{2}$ \\ ${ }^{1}$ M.N. Miheev Institute of Metal Physics of the Ural Branch of the Russian Academy of Sciences, \\ 62013718 Sofia Kovalevskaya Str., Ekaterinburg, Russia \\ ${ }^{2}$ Ural State University of Economics, 8 Marta/ 62/45Narodnaya Volya Str., 620144, Ekaterinburg, \\ Russia
}

\begin{abstract}
The authors consider the technology of processing meat and meat products using high hydrostatic pressure (HHP). Based on the results of research carried out in different countries in different years and the results of our own research, the effectiveness of the use of high pressure and its role in the control and stabilization of the microflora of finished meat products and increasing their shelf life is shown. Research data indicating the possibility of using high pressure in the processing of minced meat and beef trimmings are presented. Differences in the technical parameters of the HHP technology have been established, the results show the possibility of applying a pressure value of $250 \mathrm{MPa}$, in contrast to 300 $600 \mathrm{MPa}$ used in research by foreign scientists. The results obtained on the protein component of cooked sausage products exposed to high pressure are of applied research interest and expand the research database. The authors consider the continuation of research in determining the optimal parameters of this technology, identifying the impact on the consumer properties of meat products, and developing organizational and methodological measures to increase the commercialization of high hydrostatic pressure processing to be promising areas.
\end{abstract}

\section{Introduction}

Globalization market processes and the growing demand for food products contribute to the dynamic development of food industries based on innovative technologies. At the level of the world community, much attention is paid to non-thermal food processing in order to identify potential as an effective method.

The interest to the effect of high hydrostatic pressure on food products (milk, vegetables and fruits), discovered for the first time at the end of the 19th century by Bert Hite, resumed a few decades later as an alternative to preservation by the traditional method, which was based on heat treatment. The true potential of high pressure as an innovative method in

\footnotetext{
${ }^{*}$ Corresponding author: cafedra@list.ru
} 
food technologies was recognized only in the mid-80s [1], which allowed its effective use in the food industry. According to Wael M. Elamin et al., [2], high-pressure processing has demonstrated great capabilities, spreading almost exponentially around the world, especially in the vegetable $(35 \%)$ and meat $(29 \%)$ industries, in the production of beverages, including juices, seafood processing, and other food products, including condiments, sauces, soups, and dressings. Moreover, several processed cured meat products, such as ham and salami, are currently available on the market in Europe, the United States, Japan, and Canada [3].

The high demand for meat products in the consumer market also contributes to its dynamic development using innovative technologies. One of the trends in the consumption of meat products is the requirements for quality and safety, naturalness and preservation of freshness, and in order to harmonize these requirements in the context of the more complex and longer in time and geographical coverage food supply chains, it is required to put in place new processing technologies in the meat industry.

High hydrostatic pressure (HHP) as a non-thermal food preservation technology is used to improve microbiological safety and extend the shelf life of processed food products. HHP is an attractive non-thermal processing for meat products to avoid their contamination after processing, emphasize M. Hugas et al. [4], considering high pressure as a model, soft technology in meat processing. This is the main emergent preservation technology with great prospects for its application in the meat industry, mainly used as a final disinfection measure after the production and/or packaging procedures [4].

Historical aspects, general characteristics of the food processing technology, including meat processing using high hydrostatic pressure, description and principles of the process, the current commercial status of this technology, and other technical aspects have been studied in detail and are sufficiently fully presented in the scientific literature $[5,6]$. The influence of pressure on meat and meat products has been widely studied by foreign and domestic researchers, and the use of pressure for meat and meat products is described in various articles $[7,8,9]$.

Agreeing with the opinion of I.V. Noga [10] about the need for developing common criteria and recipes in order to select the optimal combination of different processing parameters for different types of meat products, the authors note that the issues of applied research interest are not only technical, but also organizational and methodological ones, which contribute to increasing the level of commercialization of this technology. It is important to develop and adapt the provisions of the conceptual technology platform to the Russian reality. Thus, the purpose of the research, the main provisions of which are reflected in this article, is to develop proposals for the formation of a holistic theory of the use of high hydrostatic pressure in the processing of meat products based on the available results and experience of our own research in this area.

\section{Methods}

In the implementation of this goal, bibliographic, systemic methods, analysis and synthesis were used. The works, which reflect the results of scientific research by foreign and domestic authors in the field of using high hydrostatic pressure in the production of meat products, formed the theoretical and methodological basis of research.

The test unit for hydrostatic processing of samples (Fig. 1.) was developed at the M.N. Mikheev Institute of Metal Physics, Ural Branch, Russian Academy of Sciences (Ekaterinburg). The technical characteristics of the unit are the possibility of using high pressure in the range from $250 \mathrm{MPa}$ to $2000 \mathrm{MPa}$ in the temperature range from 20 to $250^{\circ} \mathrm{C}$. 

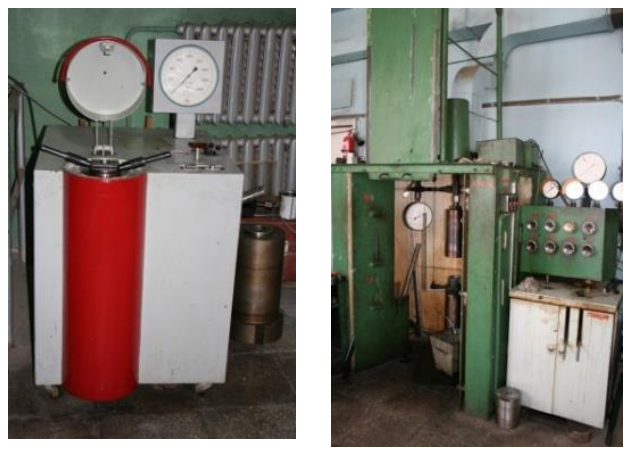

Fig. 1. Hydrostat and laboratory unit M-20

The objects of study at different stages were samples of minced mechanically deboned chicken, samples of beef meat in the form of beef trimmings, boiled sausage products sausages Doktorskie of the highest grade, packed under vacuum, semi-finished minced meat products. In each study group, a control and an experimental group were allocated based on the use of HHP processing. Sensory characteristics, physicochemical and microbiological indicators were determined in all studied samples; quantitative and qualitative analysis of the protein component was carried out in sausages.

\section{Results and Discussion}

Increasing consumer demand for minimally processed, chemical-free and healthier meat has led to the development of alternative traditional technologies, emphasize researchers in [11]. High pressure processing is known as non-thermal intervention, with the main purpose of extending the shelf life and increasing the safety of meat. To date, some material has already been accumulated that allows us to state the advantages of this method in comparison with others in terms of increasing the shelf life for finished products, for example, low-fat pastrami, Strassburg beef, export sausage and Cajun beef [9] and others.

According to the authors, minced meat systems that are widely used in industrial and catering enterprises as a raw material component in the production of semi-finished and sausage products and those sold as a complete finished product are of interest as objects of study. For research, there was selected mechanically deboned minced chicken meat, which is widespread due to the economical and physical availability of raw materials. However, it is well known that minced meat systems are a category of raw materials with a high risk of contamination by microorganisms. The methodology and research results are presented in work [12]. The main conclusion was the rationale for an up to 10-day increase in the shelf life of chilled mechanically deboned minced chicken made using the HHP processing mode and the absence of a negative effect on the properties of the minced meat, which determine its quality and nutrition value. Studies of processed objects in terms of safety indicators are important in assessing the effectiveness of the HHP technology. The scientific work [5] provides data on the content of biogenic amines, nitrate substances, migration of compounds from packaging, allergens in meat products that were processed under high pressure. In our studies, in the determination of cadmium, arsenic, mercury and lead, pesticides of the DDT and $\mathrm{HCH}$ groups, it was found that the control and experimental samples of mechanically deboned minced chicken contained the listed substances in quantities that did not exceed the maximum concentration established by regulatory documents both on the day of manufacture of the product and at all control points $(5,7$ and 
10 days of storage) and it was found that high pressure processing does not lead to their changes in dynamics.

The effectiveness of this method in increasing safety is determined in relation to pathogenic microflora. According to [13], Listeria varies widely with varying infection rates from $5 \%$ to $62 \%$ among raw red meat, poultry and some meat products. The material for our study was samples of beef meat trimmings. Experimental groups were modeled, samples of which were injected with pure cultures of microorganisms of the genus Salmonella, the genus Listeria, as well as Coliform bacteria. The control group consisted of samples with a baseline content of microorganisms. The research methodology is presented in [14]. The results obtained are consistent with the available data and allow us to recommend the use of high hydrostatic pressure as a method for solving the problem of contamination of raw meat and finished meat products. In contrast to the HHP values of $350 \mathrm{MPa}$ for Salmonella bacteria and $375 \mathrm{MPa}$ for Listeria monocytogenes bacteria, recommended in [13], our own research has shown the effectiveness of using a value of 250 $\mathrm{MPa}$.

The use of HHP can inactivate microorganisms, with little or no effect on the nutritional and sensory aspects of food quality, emphasize E. Hogan et al. [15]. However, in studies [16], boiled chicken breast meat prepared from samples under pressure had a harder texture than the control. M. Uyarcan, S. Kayaardi [17], studying the color and sensory properties of beef loin steaks subjected to combined high-pressure processing and pickling at $550 \mathrm{MPa}$, revealed a "bleaching/brightening" effect on the color of samples. Sanita Sazonova et al. [18] indicate that one of the problems behind the color loss is a possible decrease in the nutritional value of products processed using this technology. It is known that the pressure level from 300 to $600 \mathrm{MPa}$ led to the oxidation of lipids in a number of meat products, while changing their lipid content and the fatty acid composition of phospholipids and free fatty acids. One of the directions of our research was to determine the biological value of meat products that were processed by the HHP method. It was determined using the example of fully cooked sausage products [19].

Earlier, based on the data available in the literature, we developed an algorithm for complex assessment of the qualitative side of the protein component, which was used in the analysis of the studied samples. It was found that the protein ingredients of the studied samples met modern requirements for the biological value of products. Cooked sausage products had high indicators of amino acid score (116.6 and 121.1), equal utility coefficients of amino acid composition (0.7), their biological values were 66.3 and 70.5 , respectively. Moreover, the biological value and the utility coefficient of the amino acid composition in the analyzed initial protein system of the sample exposed to HHP are notable for higher values in comparison with the control sample.

\section{Conclusions}

1. Processing meat and meat products is an effective way to control the microflora in meat and meat products, thereby extending their shelf life. HHP has been proven to be effective against Salmonella pathogens, Listeria monocytogenes bacteria, and Coliform bacteria. However, further research is required to validate the process in terms of the effect of HHP on other types of microorganisms.

2. The values of basic significance in the methodology of processing meat products in terms of the parameters used are established. The analysis of data reported in the literature indicate a wider use of the HHP values starting from $300 \mathrm{MPa}$, the studies of domestic scientists, including our own, the value of $250 \mathrm{MPa}$ is used, and the applicability and effectiveness of this parameter is confirmed by the results, which are manifested including, but not limited to, in the preservation of sensory characteristics. This aspect indicates the 
need to continue research and develop unified technical criteria for HHP in meat processing, such as pressure value, exposure time and temperature regime.

3. The HHP processing is an effective non-thermal means of improving food safety and shelf life for meat products as a post-process intervention. Research shows the possibility of using high pressure in the segment of minced meat and other types of meat raw materials, while decisions on the use of the technology can be determined by the implementation of requirements for compliance with the control of the microflora of raw materials and its stabilization and the fight against pathogens.

4. The data obtained, characterizing the qualitative aspect of the protein component of finished meat products subjected to high pressure processing, significantly expand the research database, but also indicate the need to continue research in the field of the HHP effect on the quantitative and qualitative study of lipids and fatty acid composition, mineral value of products. One of the objectives of the food industry in the implementation of any technology that contributes to the commercialization of the technology and the competitiveness of the industry as a whole is the preservation of sensory characteristics and food components, which provide the value of the product for consumers.

5. Food business operators considering the use of stand-alone high pressure meat processing plants should be held accountable in accordance with applicable quality and safety legislation and ensure that appropriate traceability and recall systems are in place. It is necessary to resolve issues of the need for appropriate labeling (or lack thereof) of HHP processed meat and meat products at the legislative level. It is of interest to identify the acceptance by Russian consumers of new technologies in the processing of meat products.

6. The development of acceptable processing levels for raw and ready-to-eat meat and meat products, starting from $250 \mathrm{MPa}$ with a short exposure time at ambient temperature, environmental friendliness and waste-free technology, public awareness will contribute to the commercialization of the new method.

\section{Acknowledgements}

The authors express their gratitude to the translator and editor for their professional approach to work, to the colleagues for their support in the course of working on the manuscript, to the publishing houses of the journals that provide free access to the materials in the field of non-thermal processing of food products and to the Russian Foundation for Basic Research for the financial support in the implementation of Project No. 18-016-00082 "Influence of processing by high hydrostatic pressure (up to 10,000 atmospheres) on physical properties, microbiological points and shelf life of various food products".

\section{References}

1. J. Pou K. R. International Journal of Agriculture Sciences, 7(12), 801-808 (2015)

2. W. M. Elamin, J. B. Endan, Y. A. Yosuf, R. Shamsudin, A. Ahmedov. Journal of Engineering Science and Technology Review, 8(5), 75 - 83 (2015)

3. R.Taddei, F.Giacometti, L. Bardasi, P. Bonilauri, M. Ramini, M. Fontana, P. Bassi, S. Castagnini, F. Ceredi, M. Pelliconi, A. Serraino, F. Tomasello, S. Piva, E. Mondo, G. Merialdi, Italian Journal of Food Safety, 9(2) 132 - 136 (2020)

4. M. Hugas, M. Garriga, J.M. Monfort, Meat Sci., 62, 359 - 371 (2002)

5. Y. Tao, D. Sun, E. Hogan, A. L. Kelly. Emerging technologies for food processing, 3 87 (2014)

6. M. Campus, Food Engineering Reviews, 2(4), 256 - 273 (2010) 
7. N.A. Gorbunova. All about meat, 1, 45 - 47 (2012)

8. L. Vinnikova. Eastern-European journal of enterprise technologies, 3/10 (75), 31 - 36 (2015)

9. M. M. Hayman, I. Baxter, P. J. Oriordan, C. M. Stewart. J. Food Prot., 67(8), 1709 1718 (2004)

10. I.V. Noga. Physics and high pressure technology, 16(3), 126 - 136 (2006)

11. M. Garriga, T. Aymerich. Safety of Meat and Processed Meat, $183-208$ (2009)

12. L. A. Donskova, A. Yu. Volkov, V. V. Kotkova. XXI Century: Resumes of the Past and Challenges of the Present plus, 4(48), 182 - 187 (2019)

13. J. M. Jay, M. J. Loessner, D.A. Golden. Modern food microbiology, 527 - 537 (2014)

14. A.Yu. Volkov, L. A. Donskova, V. V. Kotkova. International journal of appliedand fundamental research, 11, 92-96 (2019)

15. E. Hogan, A. L. Kelly, Da-Wen Sun. Emerging Technologies for Food Processing, 3$32(2005)$

16. K. Tananuwong, T. Chitsakun, J.Tattiyakul, Food Sci., 77(11), 321 - 327 (2012)

17. M. Uyarcan, S. Kayaardi. Italian journal of food science, 31(4), 573 - 592 (2019)

18. S. Sazonova, R. Galoburda, I. Gramatina. Baltic Conference on Food Science and Technology FOODBALT «Food for consumer well-being» 17 - 22 (2017)

19. L.A. Donskova, V.V. Kotkova, A.Yu. Volkov. Bulletin of Buryat State Academy of Agriculture, 4(49), 99 - 106 (2017) 